\title{
O MITO DO GRÊMIO IMORTAL NO JORNAL ZERO HORA A PARTIR DA SEMIÓTICA BAR- THESIANA
}

\author{
VINÍCIUS HENRIQUE FONTANA \\ Universidade Federal do Rio Grande do Sul \\ Porto Alegre, Rio Grande do Sul, Brasil \\ e-mail: vhfontana89@gmail.com \\ MARCIO TELLES \\ Universidade Federal do Rio Grande do Sul \\ Porto Alegre, Rio Grande do Sul, Brasil \\ e-mail: tellesdasilveira@gmail.com
}


O MITO DO GRÊMIO IMORTAL NO JORNAL ZERO HORA A PARTIR DA SEMIÓTICA BARTHESIANA ${ }^{1}$

Resumo: Este artigo tem como finalidade a investigação do mito da "imortalidade" atribuída ao Grêmio Foot-ball Porto Alegrense dentro das matérias do jornal Zero Hora, periódico de maior circulação no Estado do Rio Grande do Sul. São analisados exemplares referentes aos jogos mais "dramáticos" da equipe entre 26/11/2005 e o início de 2011, sob a ótica de autores como Roland Barthes e Hilário Franco Júnior. Palavras-chave: Grêmio; mito; jornalismo esportivo.

\section{EL MITO DE GRÊMIO IMORTAL EN EL PERIÓDICO ZERO HORA PAR- TIENDO DE LA PERSPECTIVA DE ROLAND BARTHES}

Resumen: Este artículo tiene como finalidade la investigación del mito de la "imortalitad" achacada al Grêmio Foot-ball Porto Alegrense en el noticiário del periódico Zero Hora, lo de mayor circulación en Rio Grande do Sul. Son analisados ejemplares acerca de los partidos más "dramáticos" del equipo entre 26/11/2005 y el princípio de 2011, bajo la visión de autores como Roland Barthes y Hilário Franco Júnior. Palabras-clave: Grêmio; mito; periodismo desportivo.

THE MYTHOLOGY OF "GRÊMIO IMORTAL" INSIDE THE NEWSPAPER ZERO HORA THROUGH BARTHES' SEMIOTICS.

Abstract: This paper has as an objective investigate the construction of Gremio's immortality myth inside the reports of the Brazilian newspaper Zero Hora. The analysis covers the reports about some of the most dramatical matchesin Grêmio's history between 26/nov/2005 and the beginning of 2011, under the perspective of authors such as Roland Barthes and Hilário Franco Júnior. Keywords: Grêmio; mith; sports journalism.

1 O presente artigo deriva da monografia "Mitologias no Jornalismo esportivo, o mito da imortalidade gremista" de Vinícius Henrique Fontana, co-orientado por Marcio Telles e Alexandre Rocha da Silva. Disponível em http://www.lume.ufrgs.br/handle/10183/33667. 


\section{INTRODUÇÃO}

Onze guerreiros de cada lado se perfilam estrategicamente na arena para começar a partida. Há um alvo: o gol. Há o atacante e o defensor. Uma ocupação de espaços. Um vencedor e um derrotado. Há nações, legiões de torcedores, de fiéis. Por mais que esse trecho não possua quase nenhuma referência direta ao esporte, utilizando terminologia bélica (guerreiros, alvo, legião, atacante, etc.), todos sabem que se trata de uma partida de futebol. E tais "falas" reproduzem-se e, em determinados níveis, são criadas pelos jornalistas, os principais responsáveis pela reconstrução de eventos esportivos, especialmente se tratando de futebol.

Esse artigo visa a retomar a teoria dos mitos escrita por Barthes entre 1954 e 1956, publicada em 1957 na obra "Mitologias", na qual o autor define o que é mitologia, aferindo a determinados componentes míticos por ele apontados e qual o seu modus operandi, tendo como foco sua aplicabilidade à dimensão jornalística, mais especificamente como o jornal Zero Hora construiu (e constrói) o mito do "Grêmio, Imortal Tricolor". "Imortalidade", aqui, é definida como a capacidade de superação do Grêmio perante uma situação adversa, e esse eixo condutor levou à definição do corpus do artigo. Partindo da ideia inicial de que o mito é uma fala, busca-se o esclarecimento das cadeias metalinguísticas que este apresenta e como a sua identificação é crucial para o entendimento do mito dentro da cobertura realizada das partidas mais importantes do Grêmio Foot-ball Porto-Alegrense entre os anos de 2005 e 2010.

A escolha por uma análise semiológica advém da ideia de que essa se apresenta "como a disciplina cujo método de trabalho serve para formular hipóteses sobre os sentidos possíveis das mensagens, das formas e das práticas significantes" (CODATO e LOPES, 2007, p.207). Assim, desvendando a complexidade de um objeto para além da sua aparência, é possível apreciar narrativas de origem mítica.

A seleção do corpus abrange 22 exemplares que repercutiram partidas importantes nas quais o Grêmio tenha conseguido o escore positivo da partida nos 25 minutos finais de partida (jogos da Copa Libertadores da América, Copa do Brasil, Campeonato Gaúcho e Campeonato Brasileiro), sendo que as matérias analisadas traziam elementos de interesse à pesquisa (uso da expressão "imortal”, vocabulário bélico, exaltação da garra da equipe como ínsita à sua essência, entre outras características afins). 
O MITO DO GRÊMIO IMORTAL NO JORNAL ZERO HORA A PARTIR DA SEMIÓTICA BARTHESIANA

\section{MITOLOGIA: PRESSUPOSTOS}

Para compreender o que é o mito, é necessário identificar certos limites históricos e condições de funcionamento . Segundo Barthes, "a mitologia só pode ter um fundamento histórico, visto que o mito é uma fala escolhida pela história: não poderia de modo algum surgir da natureza das coisas" (1980, p.131). O limite histórico que se impõe ao mito é ficcional, é uma prospecção do que seria seu limiar, já que pensar um ponto preciso seria tão mítico quanto o mito em si. O mito é um sistema de comunicação, é uma fala suscetível de ser julgada por um discurso. Não é definido pelo objeto de sua mensagem, e sim pela maneira como a profere, sendo limitado formal e não substancialmente.

Barthes (1980) afirma que o mito não pode ser definido nem pelo seu objeto nem pela sua matéria, pois esta pode ser arbitrariamente dotada de significação. A fala mítica é formada por uma matéria já trabalhada em vista de uma comunicação apropriada, qual seja, adquirida. Todas as matérias primas do mito pressupõem uma consciência significante, sendo essa a razão pela qual se pode raciocinar sobre o mito de modo apartado de seu correspondente fático. Ou seja, não precisamos analisar o que seria a referência (no caso deste trabalho, o Grêmio). É preciso pensar na ideia que se tem do esporte, qual seria a impressão do real defronte à realidade objetiva.

A mitologia é apenas um fragmento da ciência dos signos. $O$ mito depende do apoio de uma ciência geral extensiva à linguística, ou seja, a semiologia' . O mítico opera em constante regime de dualidade e, como a semiologia, postula uma relação entre dois termos - um significante e um significado -, tornando-se um campo fértil para interpretarmos a mitologia. Ao estuda-la, relacionamos objetos de ordem distinta, não constituindo uma igualdade, mas uma equivalência.

O mito é um sistema particular, construindo-se a partir de uma cadeia semiológica pré-existente. O signo, qual seja, a associação de um significante com um significado (SAUSSURE, 2006), é transfigurado por Barthes em significante no mito. Exemplificando, pode-se pensar no brasão de uma equipe de futebol: em um primeiro sistema ou, pensando figurativamente, no pri-

1 A semiologia é definida por Barthes (1957) como uma ciência das formas, visto que estuda as significações independentemente do seu conteúdo. A mitologia faz parte, simultaneamente, da semiologia como ciência formal e da ideologia como ciência histórica, estudando ideias em forma (objeto material). 
meiro grau da cadeia, o brasão é signo; no segundo, ele será equivalente ao significado, o que o torna sujeito passivo na atribuição de significados como garra, futebol ofensivo, futebol-arte (como é o caso da Seleção Brasileira), etc. Esse é um atributo fundamental do mito: ele "vislumbra" nas matérias primas da fala mítica um substrato de pura função significante. A unidade provém do fato que todas são reduzidas ao simples estatuto de linguagem. O mito apenas considera uma totalidade de signos, um signo global, o termo final de uma primeira cadeia semiológica, conforme proposta por Saussure $(2006)^{2}$. É esse termo final da primeira cadeia que se transformará no primeiro termo do sistema aumentado que o mito constrói (BARTHES, 1980).

Conforme Barthes (1980), no mito existem dois sistemas semiológicos. O primeiro é linguístico, chamado por Barthes de linguagem-objeto: eis a base que o mito utiliza para construir seu próprio sistema. $O$ segundo é o próprio mito, que é definido como metalinguagem, sendo uma segunda língua que fala sobre a primeira ${ }^{3}$. Refletindo acerca de uma metalinguagem, o semiólogo não deve se preocupar com a composição da linguagem-objeto, sequer pode ocupar-se com o detalhe do esquema linguístico: dele somente terá que considerar o termo total ou signo global, e apenas na medida em que tal se presta ao mito. Assim, não é necessária a análise dos signos futebolísticos para compreender o que é mitologia no futebol. A cadeia que sobrepõe a linguagem-objeto acaba esvaziando essa estrutura e dando a ela uma nova conotação.

O significante pode ser encarado, no mito, através de dois pontos de vista diferentes: ele pode ser o termo final do sistema linguístico ou termo inicial do sistema mítico. A fim de melhor trabalhar com tais conceitos, Barthes (1980) define o significante do primeiro sistema como sentido. Para

2 Para saber mais: SAUSSURE, Ferdinand. Curso de linguística geral. Cultrix: São Paulo, 2006.

3 Conforme Bernard Toussaint (1978), Barthes revisa a sua teoria posteriormente, atribuindo a este primeiro sistema a ideia de imagem figurativa, ou seja, os códigos que antecedem a analogia, considerados denotativos. Em sequência, vêm os códigos da conotação, impondo uma analogia (que seria uma espécie de cópia dos referentes, conformando uma impressão de realidade) a fim de abstrair a imagem. Portanto, Barthes redefiniu um pouco a sua concepção de denotação/conotação, definindo-os como códigos. Tais teorias não serão abordadas neste artigo, contudo aqui estão expostas para esclarecer que "Mitologias" não é uma obra definitiva: sua reavaliação (inclusive a feita pelo próprio autor) é necessária. Também prova que não está esgotada: por mais que se critique, há conceitos e pensamentos importantes a serem apreendidos e reavaliados. 
O MITO DO GRÊMIO IMORTAL NO JORNAL ZERO HORA A PARTIR DA SEMIÓTICA BARTHESIANA

o sistema mitológico, em seu modo vazio, substantiva-se como forma. O correspondente ao significado dentro da cadeia barthesiana é denominado conceito. $O$ terceiro termo do sistema é o signo que, frente ao mito, é definido conforme processos de significação, já que o mito tem dupla função: designa e modifica, faz compreender e impõe.

\section{OS TERMOS DA MITOLOGIA E O JORNALISMO}

Podemos começar a delimitar alguns esclarecimentos a partir do primeiro termo da mitologia barthesiana: o significante mítico. Ele se apresenta de modo ambíguo: é simultaneamente sentido e forma. Enquanto sentido, o significante postula uma leitura ínsita a uma realidade sensorial. No sentido já está constituída uma significação, o que bastaria para si própria, contudo o mito acaba por transformá-la em uma forma vazia. "O sentido já está completo, postula um saber, um passado, uma memória, uma ordem comparativa de fatos, de ideias, de decisões" (BARTHES, 1980, p. 139). Ao tornar-se forma, esvazia-se a sua história e o que sobra é apenas o seu "conjunto vazio", matéria que carrega o significado mítico no segundo sistema.

A forma do sistema mitológico requer uma significação que preencha esse vazio. No entanto, não se deve incorrer no erro de crer que a forma extingue o sentido. "Ela o empobrece, mas o deixa em estado de suspensão, servindo de alimentação à forma do mito" (BARTHES, 1980, p. 140). Em outros termos, pode-se remeter a dualidade sentido-forma a um jogo de esconde-esconde entre ambos, definindo assim o mito: a forma oblitera o sentido, porém este não está morto, está escondido e o mitólogo tem a pretensão de tentar acha-lo. Imagine-se que estou em minha casa e olho para além da janela, através da vidraça. É possível ver duas coisas ao mesmo tempo: ou o vidro ou a paisagem, porém jamais conseguirei focar ambas ao mesmo tempo. O mesmo ocorre com o sentido e a forma. Elas não estão no mesmo ponto, pois jamais entram em conflito ou tangência. No mito, "a forma permanece vazia mas presente, o sentido ausente e, no entanto, pleno" (BARTHES, 1980, p. 145).

Para ter relevância no mundo, o sentido acaba se munindo de um conceito (BARTHES apud TOUSSAINT, 1978). O conceito pode ser visto como o correspondente mítico do significado no sistema linguagem-objeto. Ele acaba absorvendo a história que a forma "suprime" do sentido, pois é um termo determinado: ao mesmo tempo ele é histórico e intencional. "O con- 
ceito estabelece uma cadeia de causas e efeitos, motivações e intenções. Através do conceito, toda uma história nova é implantada no mito" (BARTHES, 1980, p. 140).

Por fim, há o termo final: a significação, que é definida como sendo a associação da forma com o conceito. $O$ vácuo da forma com a representação de real do conceito unem-se na significação, o que gera o mito. "Ele é o único estrato da cadeia de metalinguagem que tem uma plenitude em sua maneira de apresentar-se ao mundo" (BARTHES, 145, p.143). No mito, tanto a forma quanto o conteúdo estão presentes e manifestos. Os termos não se escondem, contudo o mito acaba por deformá-los. Barthes (1980) define que a origem linguística do primeiro termo (sentido), como provém de modo "esvaziado", oferece-se como matéria. A forma adquire um caráter de lugar, proximidade, limite espacial, o que lhe aproxima do real. Já o conceito é uma rede mais abstrata de um saber histórico e, portanto, coletivo: seu embasamento está nas conexões tênues que se estabelece entre um e outro (BARTHES, apud TOUSSAINT, 1978). E é precisamente a forma que é o foco do reprodutor de mitos, no caso, a imprensa, tendo em vista que o conceito preenche a forma sem ambiguidades, configurando-se como se fosse um sistema simples de significação literal. Ramos e Jardim (2002) complementam a teoria barthesiana ao assumir que a fala jornalística transcende o linguístico, é incorporada pela prática. O jornalista incorpora em sua prática o mito, se pauta por ele e, assim, não consegue fugir de sua estrutura. Assim, o mito volta-se como uma linguagem roubada, uma distorção auferida ao sentido e à forma. O mítico passa a ser uma fala despolitizada, não tendo a função de negar as coisas, e sim falar delas, naturalizando a história e normalizando diversas questões complexas. O debate está centrado no mito sem que o sentido seja tangenciado. Falar sobre o mito, tentar criticá-lo "acriticamente", serve mais para reproduzi-lo do que desconstruí-lo.

Flávia Dourado Maia (2010), ao analisar a obra de Bird e Dardene (1988, 2009), conclui que as notícias ocupam hoje lugar de modelo de cultura que antes estava adstrito ao mito em culturas antigas. Verifica que as notícias ao codificarem informações sob a forma de narrativas, por meio de um processo indutivo de construção, atribuem significados simbólicos aos fatos, explicando a condição de ser no mundo e normalizando valores, acabam por unir as pessoas dentro de uma matriz comum de sentidos. Transpassando ao mito, vislumbra-se que a matriz não seria de sentidos, mas de conceitos. 
O MITO DO GRÊMIO IMORTAL NO JORNAL ZERO HORA A PARTIR DA SEMIÓTICA BARTHESIANA

\section{O 'IMORTAL TRICOLOR' NO JORNAL ZERO HORA}

Franco Júnior (2007) afirma que o futebol é uma linguagem em si e uma metáfora de outras linguagens. Assim sendo, é inegável sua natureza discursiva. O jogo produz signos muito mais conotativos que denotativos. Tais signos não são óbvios. Podemos apenas afirmar que há uma produção ampla de sentidos durante uma partida e esses têm suas bases fundamentadas em relações mais profundas do que a do jogo em si. Como toda língua, o futebol possui morfologia, semântica e sintaxe (SILVA e TELLES, 2010). A morfologia consiste no controle da bola, que é o elemento que interliga uma fala. A semântica abrange uma dupla relação - jogar com a bola (eixo sintagmático) e sem ela (eixo paradigmático). A sintaxe, por fim, é entendida como a organização dos participantes em um campo conectados entre si, compondo um sistema, um modelo de jogo. Esses elementos complementam-se e suscitam o discurso inerente ao futebol, e não sobre ele (SILVA e TELLES, 2010). Além da própria linguagem do jogo há as arquibancadas, não um além-linguístico ou uma fala apartada, mas uma complementação com inferências diretas ao que a imprensa produz quando cobre uma partida de futebol.

A fala mítica é definida mais pela sua intencionalidade do que a literalidade. Sabemos que a intenção de denominar o Grêmio como "Imortal Tricolor" é mais forte do que o próprio significado do termo. No entanto, essa intenção se petrifica e figura-se literal. $O$ mito sempre se dirige à pessoa que o recebe devido ao seu caráter histórico, porém o contrário não ocorre. Caso alguém nunca estivesse em Porto Alegre e fosse assistir a um jogo do Grêmio em que ele vença nos minutos finais, pode não se surpreender com a dita "imortalidade". Contudo, ao ler os jornais pela manhã e identificar as definições dadas ao "imortal", está sendo atraída pelo mito revestido da história que o produziu. $O$ receptor acaba por recuperar a generalidade de uma fala, tornando-a translúcida, pura e inocente (BARTHES, 1980, p. 146).

A denominação "Imortal Tricolor" não nasceu na imprensa, ou ao menos não é a história aparente e provável. Ela está inclusive no hino do clube, datado de 1954, porém possui uma função mais estética do que propriamente mítica.

Se, por um lado, o hino imortaliza o Grêmio pela sua história (50 anos de glória, tens imortal tricolor), por outro lado, a 'nova' imortalidade, além da história, está conjugada a outra série de enun- 
ciações relacionadas a um discurso religioso, da ordem da crença, posto em operação tão somente a partir de uma cena enunciativa específica" (LORENZ, 2009, p. 104)4

O site oficial do clube relata que a ideia de imortal tricolor como a entendemos hoje surgiu em 1994, após uma série de vitórias difíceis quando a equipe não contava com atletas de grande qualidade. O colunista da Zero Hora, Wianey Carlet, afirma, em coluna publicada no dia 02/05/2009, que a "imortalidade tricolor [foi uma] jogada de marketing, espontânea neste caso, saída da torcida. Surgiu nos vitoriosos anos de 1980/90 quando o Grêmio marcava gols salvadores nos últimos minutos". Verifica-se que a ideia de imortalidade já vem altamente mitificada desde uma época na qual, supostamente, a imprensa não era reprodutora direta do mito. Porém, verifica-se uma "institucionalização" do mito dentro do jornal Zero Hora a partir do jogo Grêmio contra Náutico, em Recife, no dia 26/11/2005, conhecido como "Batalha dos Aflitos". Reforçando essa tese está o trabalho de Lorenz (2009), verificando que a imprensa, nos anos 1980, definia o Grêmio comumente por termos como "heróis", "raça”, "garra”, “talento", “qualidade”, "time brasileiro", "batalha”, "criatividade”, "força”, "técnica”, "futebol gaúcho", entre outras, sem citar "imortal” ou qualquer derivativo. Nos anos 90 a imortalidade ainda não está aparente, porém qualidades a ela atribuídas pululam nas páginas dos jornais: "heróis”, "raça”, "garra”, "competência”, “copeiro”, “inacreditável”, "determinação”, "gaúcho”, "batalha”, etc., sendo visível que definições como "talento", "criatividade" e "futebol brasileiro" não mais são recorrentes. Já em 2005 o Grêmio passou a ser referido por termos como "heróis", "garra”, "time gaúcho", "alma castelhana”, “inacreditável”, "copeiro" e "imortalidade" (LORENZ, 2009).

Pontua-se que estipular uma origem precisa é um mito fundador, porém tal recorte temporal foi realizado a fim de viabilizar um corpus de pesquisa, sendo que se compreende que, de fato, a "fixação" do mito se deu após a partida referida supra. Esse entendimento é apoiado em Lorenz (2009), que identificou a reiteração dos dois jornais gaúchos de maior vendagem (Zero Hora e Correio do Povo) que o ponto inicial do novo entendi-

4 Essa referência nos leva a crer que a instituição Grêmio viu uma grande oportunidade para adotar uma marca facilmente identificada com o torcedor. 
O MITO DO GRÊMIO IMORTAL NO JORNAL ZERO HORA A PARTIR DA SEMIÓTICA BARTHESIANA

mento de "imortalidade" surgiu após a "Batalha dos Aflitos 56 ".

\section{ELEMENTOS DO MITO}

Verifica-se uma construção em comum nas narrativas do jornal quando cobre partidas de futebol: costuma obedecer a uma ordem cronológica dos fatos narrados, não sem antes fazer uma síntese do que ocorreu, aos moldes de um lide, já carregada de valorações a respeito do acontecimento. Sendo assim, a primeira divisão realizada para análise do mito consiste na narrativa pré-jogo, na da partida e na pós-jogo. Por fim, semanticamente é averiguado que o falar mítico vem cotejado de figuras míticas, em especial as de matriz bélica e religiosa. Destaca-se que a cisão em tais categorias é feita somente a fim de melhor explicar e estabelecer técnicas metodológicas para facilitar o trabalho de pesquisa e de compreensão do que se busca explicitar. O mito é holístico e os conceitos que o formam estão presentes em toda a fala, sendo indissociável fora de um substrato ideal de pesquisa.

Primeiramente, verifica-se que a fala mítica dentro do jornal Zero Hora não discorre acerca do clube como uma organização abstrata, mas como um ser orgânico, tátil e conversacional. O Grêmio não é uma aglomeração de pessoas tão somente, ele é uma própria pessoa, um ser vivo, tanto que as falas que antecederam, por exemplo, à "Batalha dos Aflitos", tratam o jogo como "sobrevivência do clube", "clube com 102 anos de vida", o que de fato mostra um substrato prévio, entretanto ideal, para a fomentação de um mito acerca da "imortalidade". Eis o que se amolda nos jornais seguintes: a criação de uma expectativa de que o Grêmio é essa pessoa, porém capaz de superações sobre-humanas, o que o diferencia, tornando-o capaz de feitos míticos. É um herói que, após uma batalha hercúlea, sai ferido, porém vencedor, capaz de superar desafios ainda maiores. Essa percepção ocorre especialmente no dia antecedente ao jogo decisivo, sendo de destaque as coberturas realizadas nos dias 26/11/2005, 06/06/2007 e 20/07/2007 ${ }^{\text {. }}$.

5 Vide edições do Correio do Povo do dia 28/11/2005 e da Zero Hora do dia 26/11/2005.

6 No meu trabalho monográfico (FONTANA, 2011), delimitei o corpus de pesquisa em 22 exemplares do jornal Zero Hora repercutindo o dia da partida e o seguinte. As datas foram escolhidas em razão do Grêmio ter obtido a vitória faltando, ao menos, 25 minutos para o fim do tempo regulamentar. Para mais informações sobre o dado, vide a referida monografia.

7 As edições foram fotocopiadas e estão acostadas à FONTANA, 2011. 
Além dessa personalização, o mito fala sobre o significado histórico de cada partida. Faz parte do propósito da cobertura jornalística dar relevância histórica a cada jogo, seja pelo valor que de fato possui, seja por questões mercadológicas. $O$ fato que aqui interessa é o quanto isso alimenta o mito. Barthes (1980) pontua que o conceito somente é válido se for colocado dentro da história, sendo não apenas em um contexto, mas como parte integrante de uma história do presente, um continuum do que se desenvolve em um mundo "real". Esse também ocorre previamente: o jogo já está para a história e esta irá, quase de modo inevitável, invocar a imortalidade gremista. Um exemplo interessante é a cobertura do jogo Grêmio e Caxias na semifinal do Campeonato Gaúcho de 2007. Pela situação adversa que a equipe da capital enfrentava (necessitava vencer por quatro gols de diferença para avançar às finais), a edição de 20 de maio daquele ano invocou o sentido histórico daquela partida (que ainda não havia ocorrido) como sintomática da imortalidade, o que de fato tornou-se ainda mais forte após o Grêmio ter alcançado seu objetivo e o resultado.

$\mathrm{Na}$ fala que aborda o que aconteceu durante a partida, destacam-se as figuras retóricas que o jornal utiliza na cobertura. Três são as mais recorrentes: o "espaço", os "heróis" e o "outro", dentro de contextos que usualmente referenciam batalhas e rituais religiosos, que são próprias do futebol (FRANCO JÚNIOR, 2007). Tais marcas são visíveis no caso gremista como potenciadores da fala mítica. $O$ "espaço" é definido como aquele momento da fala mítica dedicado à referência do local onde a partida se desenvolveu (ou se desenvolve dentro da narrativa). Nele a imortalidade cresce: jogar no Olímpico, estádio do Grêmio à época, engrandecia a capacidade da equipe. Os torcedores presentes ajudam o ser ferido a se levantar e ter forças para seguir adiante e se superar ${ }^{8}$. Quando distante de sua "casa", há uma força transcendental do torcedor que o ajuda a superar uma situação completamente adversa, em que a partida acontece em sítio adverso - "o Grêmio venceu em um ambiente hostil, onde uma festa já estava pronta para celebrar a vitória adversária" (Zero Hora, 28/11/2005, p.5).

Ademais, há os "heróis". Há o goleiro Galatto e o meia-atacante Ânderson na "Batalha dos Aflitos". Galatto é enaltecido na matéria do dia 28/11/2005 como tendo a serenidade necessária frente às dificuldades, a perícia para encarar o desafio e o senso de responsabilidade que o torna apto

8 Vide matéria “A pulsação do Olímpico” no jornal Zero Hora do dia 23/05/2007, p.48. 
a carregar "o destino de toda uma nação" (p.7). O herói possui uma "legião de fãs" (p.7), é o símbolo de uma conquista, um mito dentro do próprio mito, reforçando-o à medida que sua figura é invocada.

Por fim, há o adversário. Ser imortal somente é válido quando se está de fato ameaçado de morte. E essa figura aterradora, dentro da fala mítica, é personificada no adversário. É curioso perceber que a lesão de algum atleta do clube oponente ao Grêmio, suas chances perdidas e as expulsões de atletas não são vistas como fatores do jogo, e sim como adjuntos à imortalidade gremista ${ }^{9}$, que então se traveste de sorte. O adversário, muito mais que reconhecer a imortalidade, sofre com ela, estando condicionado a ela de maneira quase transcendental. As tensões de jogos decisivos não são meras afetações psicológicas e erros de imperícia ou até mesmo azar. A mítica distorce uma visão mais objetiva para condicionar o seu mundo, sua visão conceitual, novamente dentro do esquema barthesiano de esvaziamento da forma de um sentido para inserção de um conceito àquele sobreposto (BARTHES, 1980).

Para que o mito se fomente, é necessária a sua naturalização. O futebol é considerado uma importante manifestação coletiva de diversas singularidades. Ele não é apenas a externalização de uma condição social-psicológica (FRANCO JÚNIOR, 2007). O condicionamento deve ser perene e, tendo em vista a extensão temporal do corpus (quase cinco anos de matérias analisadas), é permitido concluir que o mito da imortalidade já está naturalizado. Ela até pode ser por vezes contestada (como o fez Moisés Mendes na crônica do dia 21/07/2007), porém a naturalização está tão enraizada que mesmo para o mitólogo fica impossível a contemplação plenamente dissociada do próprio mito.

Foram analisadas também as fotografias das matérias. Novamente as figuras de batalha e religiosidade são recorrentes. Elas não são meros reforços, também integram a fala mítica, já que por fala não se entende somente o que é discurso oral, mas tudo que possua valor semântico (BARTHES, 1964). A seguir, alguns exemplos ${ }^{10}$ :

9 São amostras dessa conclusão as matérias do dia 24/05/2007 e 07/12/2008.

10 Para maiores referências, ver anexos à FONTANA, 2011. 


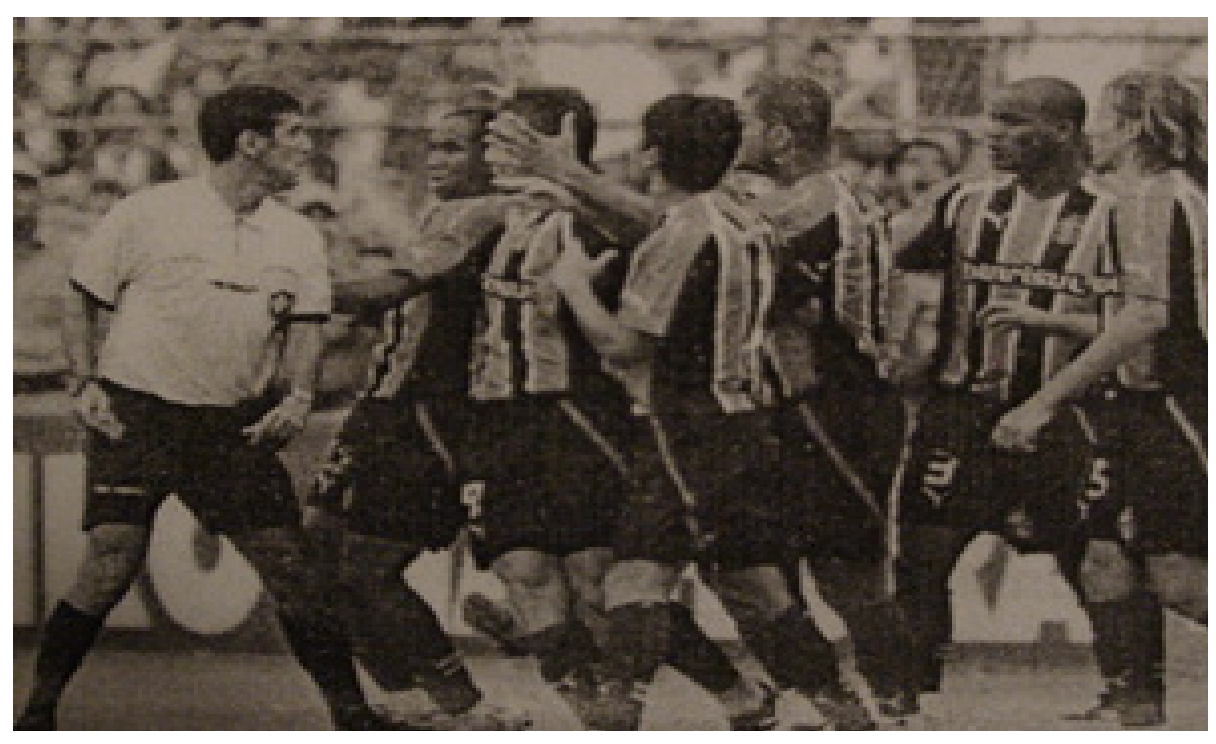

Fonte: Zero Hora, 28/11/2005

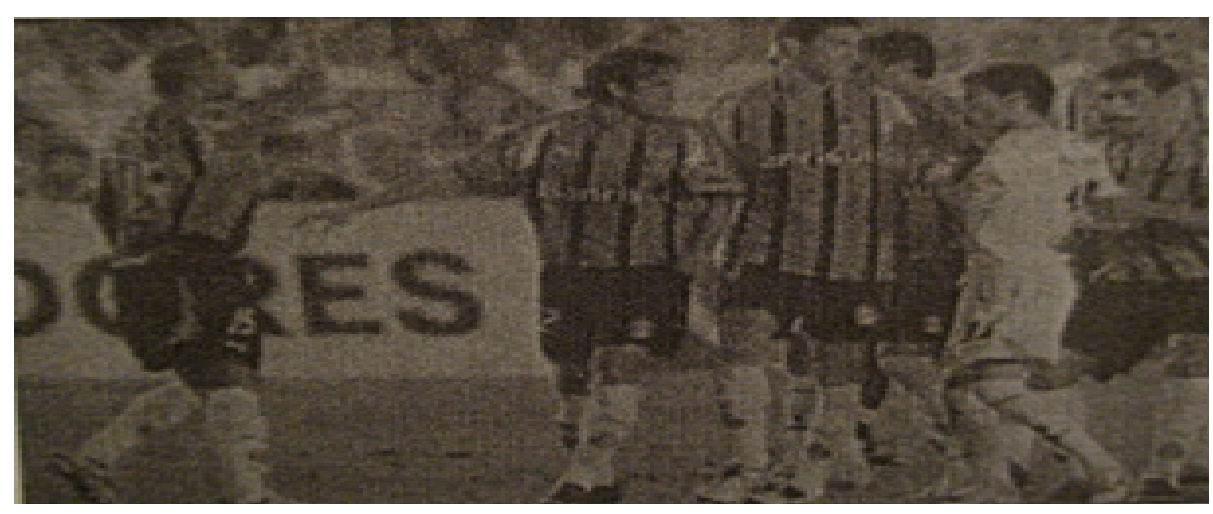

Fonte: Zero Hora, 07/06/2007

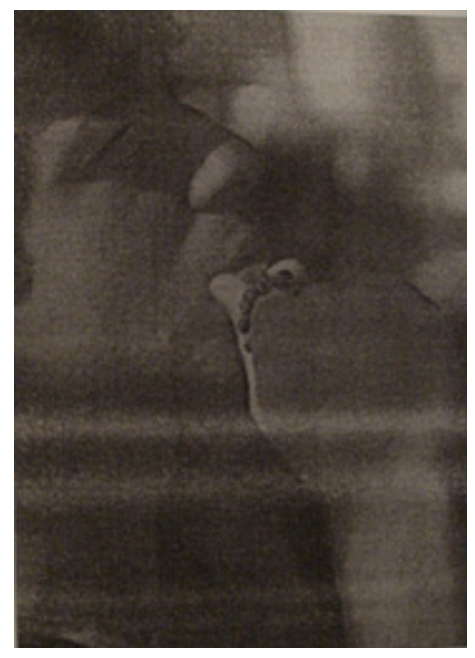

Fonte: Zero Hora, 28/11/2005 
Por fim, para verificar a repercussão do mito da "imortalidade" gremista em outros veículos de imprensa, foram realizadas buscas nas editorias de esportes dos sites dos jornais "O Estado de São Paulo" e "Folha de São Paulo" entre dezembro de 2008 e janeiro de 2011. Os termos pesquisados foram "imortal" e "imortalidade". Verificou-se que a visão dada por ambos os veículos abarca duas perspectivas: a primeira é a mera reprodução de um discurso oficialista, ou seja, do próprio Grêmio, acerca de sua imortalidade. Ela se reflete nas entrevistas dadas por dirigentes e atletas antes e após os jogos, geralmente citadas entre aspas. A segunda assemelha-se à perspectiva adotada pelo jornal Zero Hora, exaltando a "garra" e "superação" gremista, indicando que o mito também possui certa penetração na imprensa do centro do país, ainda que, aparentemente, com menor força, dadas as condições de cobertura da equipe dentro desses periódicos.

Importante diferenciar a fala mítica da fala institucional. Quando o Grêmio utiliza a marca "imortal" e tenta impô-la ao seu produto, não mais se fala em mito, pois quando há tal apropriação o mito volve-se à primeira cadeia de significação. Barthes (1980) coloca que

Existe, portanto, uma linguagem que não é mítica, é a linguagem do homem produtor: sempre que o homem fala para transformar o real, e não mais para conservá-lo em imagem, sempre que ele associa a sua linguagem à produção das coisas, a metalinguagem é reenviada a uma linguagem-objeto, e o mito torna-se impossível (BARTHES, 1980, p. 166).

O mito é, como já fora abordado, uma segunda cadeia, que se utiliza da linguagem-objeto como forma, porém esvaziando-a com o seu conceito. Este não é uma imposição, ele está naturalizado e advém da história. A linguagem política, seja publicitária ou propagandista, não confere com a linguagem mítica, tanto que Barthes (1980) define o mito como uma fala despolitizada. Não há nele relação de verdade, mas de utilização: os homens o usam e o despolitizam conforme sua necessidade dentro de movimentos históricos.

\section{CONSIDERAÇÕES FINAIS}

A mitologia somente existe devido ao reconhecimento coletivo de sua relevância. Não podemos acusa-lo de ser o assassino da história, ele é um agente da imprecisão, da distorção, porém preserva o pouco de verdade 
que um determinado fato possui. Surge exatamente da necessidade humana de cultivar uma história fora da própria história "real". E na imprensa não pode ser diferente: ela é mais um produto da estrutura humana e, tratando-se de jornalismo, uma tentativa de registro da história. No entanto, a maneira que algumas notícias são tratadas, seja por questões mercadológicas ou da própria condição do profissional, restrito a um tempo e a um espaço, faz da mídia um campo prolífero para o mito.

Eis o que foi observado neste trabalho. As rotinas de trabalho, as categorias pré-determinadas, dentro de uma fala comum, projetam um jornalismo que é menos mitólogo e mais reprodutor mítico. $O$ mito está presente na cobertura esportiva por que o seu objeto suscita um discurso que, em si, já vem assaz mitificado. A imprensa brasileira (e boa parte da mundial) ocupa-se fundamentalmente em cobrir o que concerne ao futebol. Este jogo não é apenas a percepção de uma condição social-psicológica, mas uma importante manifestação coletiva de diversas almas individuais (FRANCO JÚNIOR, 2007). A imprensa vai ao encontro desses mitos e os reproduz de maneira consciente, ampliando-o à medida que os veículos circulam e não são profundamente criticados por seus leitores (que mais se aproximam de consumidores).

Por tais constatações se verifica a relevância do mito da "imortalidade" gremista. É um mito que surge na torcida, ou ao menos em um além-imprensa, contudo cabe nos questionarmos se sua dimensão seria a mesma caso não fosse reconhecido pela imprensa. O mítico não se encerra em si, é expansível e o quanto mais é reconhecido nesse processo mais acaba por se enraizar. A memória é o que o mantém vivo em sua essência, porém a memória que não é reavivada tende ao esquecimento e, por este viés, a imprensa gera um arquivo, um arcabouço de conceitos reavivados no entremear com as formas. O mito, no futebol, é relacionado com as diversas metáforas do jogo, atreladas a seu discurso. Seu conteúdo provém de esferas alheias: do drama, da religiosidade, da guerra, etc. Esse caráter metafórico é a asseveração de uma subjetividade condicionada a uma visão mais ligada aos conceitos que aos sentidos, o que acaba por fortalecer a mítica no futebol.

Por essa ligação com a memória é que o mito do "imortal tricolor" deve perdurar. Mesmo após um tempo de latência, há um resgate quando as suas figuras retóricas surgem discursivamente dentro de uma partida. Pois o futebol é linguagem, quando a bola rola ela faz parte de uma realidade e tam- 


\title{
O MITO DO GRÊMIO IMORTAL NO JORNAL ZERO HORA A PARTIR DA SEMIÓTICA BARTHESIANA
}

bém de uma linguagem passível de discurso (SILVA e TELLES, 2010). Como discurso, há sentidos e há uma fala. Lorenz (2009) coloca que

\begin{abstract}
Esses discursos que fizeram parte da vida do Grêmio, nesses últimos 30 anos, colaboraram na construção, na ativação ou reativação de enunciados que funcionaram como máquina motriz do discurso gremista. Foi o conjunto dessas histórias, a partir das rupturas que o caracterizam, que permitem ao time ganhar contornos específicos. Não é, portanto, o time, em si, que produz isso, mas, ao contrário, tudo aquilo que foi posto em circulação no decorrer de três "quebras" , derivadas de momentos decisivos do clube (p. 120).
\end{abstract}

Todos os jornais gaúchos (e até alguns nacionais), o discurso de dirigentes, a negação do mito, a fala dos jogadores, os jogos, etc. - esses fatores somados dão a noção de "imortalidade" que é percebida atualmente. O mito pode se reformular no futuro - e provavelmente irá - em razão da mutabilidade histórica. Pode-se inclusive pensar no que Barthes (1980) afirma que é a mitificação do mito, porém essa não é uma extinção e sim uma reinvenção uma reciclagem. Parece que o mito é, de fato, mais imortal do que o próprio Grêmio.

\section{REFERÊNCIAS}

BARTHES, Roland. Mitologias. Rio de Janeiro: Editora Bertrand Brasil, 1980.

BARTHES, Roland. Elementos de semiologia. São Paulo: Cultrix, 1964.

CODATO, Henrique; LOPES, Flor Marlene E. Semiologia e semiótica como ferramentas metodológicas. In: DUARTE, Jorge; BARROS, Antonio (org.). Métodos e técnicas de pesquisa em Comunicação. São Paulo: Atlas, 2007.

FONTANA, Vinícius Henrique. Mitologias no jornalismo esportivo: o mito da "imortalidade" gremista. Monografia - UFRGS, Porto Alegre, 2011. CDROM.

FRANCO JÚNIOR, Hilário. A dança dos deuses: futebol, cultura e sociedade. São Paulo: Companhia das Letras, 2007.

JARDIM, Letícia Coronel; RAMOS, Roberto José. Althusser e Barthes: vértices espistemológicos. In: Revista FAMECOS, Porto Alegre, n 17, abril 2002.

LORENZ, Sérgio Roberto Lima. A construção discursivo-pedagógica do Grêmio Foot-ball Porto Alegrense pela mídia impressa (1983-2005). Dissertação - Ulbra, Canoas, 2009. Disponível em: < http://www.dominiopublico.gov.br/pesquisa/DetalheObraForm

$1 \quad$ N.A.: as quebras ocorreram em 1983, 1995 e 2005, conforme apontado nas páginas anteriores deste trabalho. 
.do?select_action=\&co_obra=166560 >. Acesso em 27/05/2015 às 15ho8min.

MAIA, Flávia Dourado. Jornalismo e narrativa mítica: do ideológico ao imaginário. In: http://www.intercom.org.br/papers/regionais/sul2010/resumos/R20-0637-2.pdf. Acesso em 23/03/2015 às 21h26min.

SAUSSURE, Ferdinand. Curso de linguística geral. Cultrix: São Paulo, 2006.

SILVA, Alexandre Rocha da; TELLES, Marcio. Lendo o jogo: o futebol enquanto linguagem. In: Intercom, 2010, Caxias do Sul. Disponível em: < http://www.academia. edu/8110647/Lendo_o_jogo_o_futebol_enquanto_linguagem $>$. Acesso em 27/05/2015 às 15h10min.

TELLES, Marcio. Futebol da(á) televisão: moldurações audiovisuais. Monografia - UFGRS, Porto Alegre, 2010. CDROM.

TOUSSAINT, Bernard. Introdução à semiologia. São Paulo: Publicações Europa-América, 1978.

RECEBIDO EM: 27/05/2015

ACEITO PARA PUBLICAÇÃO: 01/08/2015

\section{Vinícius Henrique Fontana}

Mestrando no Programa de Pós Graduação em Informação e Comunicação da Universidade Federal do Rio Grande do Sul (UFRGS) com ênfase em jornalismo. Especialista em Jornalismo Esportivo.Graduado pela UFRGS. Email:vhfontana89@ gmail.com.

\section{Marcio Telles}

Doutorando em Comunicação e Informação pela Universidade Federal do Rio Grande do Sul (UFRGS). Mestre em Comunicação e Informação pela mesma instituição. Recebeu o prêmio Compós/2014 de Melhor Dissertação. Integrante do grupo de pesquisa GPESC/CNPq. 
